\title{
HUBUNGAN PARITAS IBU DENGAN KETERATURAN KUNJUNGAN BALITA DI POSYANDU KELURAHAN DAHAN REJO KECAMATAN KEBOMAS - GRESIK
}

\author{
The Relationship of Maternal Parity with the Regularity of Toddler Visitingto Posyandu in \\ Dahanrejo Village Kebomas Gresik District
}

\author{
Nur Hasanah,Ernawati \\ Akademi Kebidanan Mandiri Gresik \\ hasanah-1982@yahoo.co.id,nawae_nawang@yahoo.co.id
}

\begin{abstract}
ABSTRAK
Salah satu tujuan penyelenggaraan Posyandu adalah Mempercepat penurunan Angka Kematian Bayi (AKB), anak balita dan angka kelahiran. Keadaan Angka Kematian Bayi (AKB) dan Angka Kematian Neonatal $(\mathrm{AKN})$ yang diperoleh dari angka kematian absolut masih tergolong tinggi yaitu sebanyak 4.722 bayi meninggal pertahun dan sebanyak 5.196 balita meninggal pertahun. Dalam satu hari berarti sebanyak 13 bayi meninggal dan 14 balita meninggal (Profil Jatim, 2016). Kenyataan dilapangan masih banyak ditemukan di posyandu balita yang tidak teratur berkunjung di posyandu, hal ini menyebabkan pertumbuhan perkembangan dan status gizi balita tidak terpantau.

Tujuan dari penelitian ini adalah untuk mengetahui hubungan antara paritas ibu dengan keteraturan kunjungan balita di posyandu di Kelurahan Dahan Rejo Kecamatan Kebomas Gresik.

Penelitian ini merupakan jenis analitik dengan metode cross sectional. populasinya adalah ibu yang memiliki balita yang berkunjung di posyandu di Kelurahan Dahan Rejo Kecamatan Kebomas Gresik yang diambil secara Simple Random Sampling. Dengan menggunakan uji coefisien contingency.

Dari hasil penelitian didapatkan bahwa sebagian besar ibu dengan primipara teratur dalam melakukan kunjungan posyandu yaitu sebesar $86,4 \%$, sedangkan ibu multipara/grandemultipara masih banyak yang tidak teratur dalam melakukan kunjungan ke posyandu sebesar 13,6\%. Hasil uji Fisher Exact menunjukkan nilai $\mathrm{P}$ sebesar 0,000 (lebih kecil dari $\alpha$ sebesar 0,05). Sehingga disimpulkan bahwa ada hubungan antara paritas dengan keteraturan kunjungan ke posyandu. Nilai koefisien Contingency $C$ menunjukkan nilai 0,543 hal ini menjelaskan bahwa ada korelasi yang cukup kuat antara paritas ibu dengan keteraturan kunjungan ke posyandu. Ibu dengan primipara memiliki rasa kepedulian yang besar dalam perawatan anak, sehingga untuk memantau tumbuh kembang anaknya akan rutin berkunjung ke posyandu.
\end{abstract}

Kata kunci : Paritas ibu, dan Keteraturan kunjungan balita di posyandu.

\section{ABSTRACT}

One of the objectives of Posyandu is to accelerate the reduction in Infant Mortality Rate (IMR), children under five and birth rates. The situation of Infant Mortality Rate (IMR) and Neonatal Mortality Rate (NMR) obtained from absolute mortality rates is still relatively high as many as 4,722 infants die annually and as many as 5,196 infants die annually. In one day means as many as 13 babies die and 14 toddlers die (East Java Profile, 2016). The reality in the field is still commonly found in Posyandu toddlers who do not regularly visit Posyandu, this causes the growth of development and nutritional statuses of toddlers are not monitored.

The purpose of this study was to determine the relationship between maternal parity with the regularity of toddlers visiting Posyandu in Dahan Rejo Village, Kebomas Gresik District.

This research is an analytic type with cross sectional method. The population is mothers who have toddlers who visit to Posyandu in Dahan Rejo village, Kebomas Gresik District, which were taken by simple random sampling. By using contingency coefficient test.

From the results of the study, it was obtained that the majority of mothers with parity primipara regularly visit to Posyandu were $86.4 \%$, while there were multipara/grandemultipara who did not regularly visit to Posyandu were 13.6\%. Fisher Exact test results showed a P value of 0,000 (smaller than $\alpha$ of 0.05 ). So it can be concluded that there is a relationship between parity and regularly visit to Posyandu. Contingency $\mathrm{C}$ coefficient value indicates the value of 0.543.This explains that there is a strong correlation between maternal parity and regularity visits to Posyandu. Mothers with parity primipara have a great sense of care in child care, so to monitor the growth and development of their children will regularly visit the posyandu.

Keywords: maternal parity, and Regularity of toddlers visitingto Posyandu. 


\section{PENDAHULUAN}

Posyandu merupakan salah satu pelayanan kesehatan di desa untuk memudahkan masyarakat untuk mengetahui atau memeriksakan kesehatan terutama untuk ibu hamil dan anak balita. Keaktifan keluarga dalam setiap posyandu tentu akan berpengaruh pada status gizi anak balitanya karena salah satu tujuan posyandu adalah memantau peningkatan status gizi masyarakat terutama anak balita dan ibu hamil (Adisasmito, 2007). Untuk meningkatkan status kesehatan, khususnya melalui upaya system kesehatan, pemerintah setelah menyelenggarakan pelayanan kesehatan yang dikenal dengan puskesmas yang merupakan pelayanan kesehatan primer yang dikembangkan adanya posyandu, agar masyarakat mendapat pelayanan yang mudah dijangkau.

Salah satu tujuan penyelenggaraan Posyandu Menurut Depkes RI (2006) adalah Mempercepat penurunan Angka Kematian Bayi (AKB), anak balita dan angka kelahiran. Keadaan Angka Kematian Bayi (AKB) dan Angka Kematian Neonatal (AKN) yang diperoleh dari angka kematian absolut masih tinggi yaitu sebanyak 4.722 Bayi meninggal pertahun dan sebanyak 5.196 balita meninggal pertahun. Dalam satu hari berarti sebanyak 13 bayi meninggal dan 14 balita meninggal (Profil Jatim, 2016).

Dalam upaya pencapaian kemandirian masyarakat di bidang kesehatan, peran orang tua dalam hal ini sangatlah penting bagi pertumbuhan dan perkembangan anak oleh karena itu para ibu hendaklah membawa balitanya ke posyandu untuk datang menimbang dan memeriksakan si anak. Akan tetapi belum semua ibu menyadari pentingnya membawa balitanya ke posyandu sehingga hal ini tidak dimanfaatkan oleh ibu-ibu yang mempunyai anak. Hal itu disebabkan adanya ibu yang terlalu sibuk bekerja, ibu yang mempunyai banyak anak, dan ibu yang malas membawa anaknya ke posyandu karena jarak rumah dengan posyandu terlalu jauh.

Dari studi hasil pendahuluan di posyandu Di Desa Dahan Rejo Kecamatan
Kebomas Gresik pada Juni 2018 di dapatkan jumlah seluruh balita yang ada di posyandu sebanyak 102 balita, dengan kehadiranpada bulan Maret sebanyak 82 balita (83\%), April sebanyak 76 balita (74\%), Mei sebanyak 87 balita (85\%) dengan cakupan partisipasi masyarakat yang ke posyandu masih dibawah target nasional yaitu sebesar $90 \%$. Dari ketidakteraturan kunjungan balita ke posyandu tersebut mengakibatkan tidak terpantaunya pertumbuhan dan perkembangan balita.

Keberhasilan pencapaian program posyandu terutama dalam hal keteraturan kunjungan penimbangan ke posyandu tak lepas dari faktor yang mempengaruhi yaitu peran serta masyarakat berhubungan dengan sikap, pengetahuan, pendidikan, pekerjaan, dan umur ibu balita (Notoatmojo, 2005), selain itu peran petugas kesehatan, fasilitas kesehatan, lingkungan dan lokasi serta jarak tempat posyandu juga berperan penting dalam pencapaian keberhasilan program posyandu (Latief, 2009).

Dari uraian data di atas peneliti tertarik untuk melakukan penelitian tentang hubungan paritas ibu dengan keteraturan kunjungan balita di posyandu Di Desa Dahan Rejo Kecamatan Kebomas Gresik.

\section{METODOLOGI PENELITIAN}

Penlitian ini menggunakan desain analitik metode pendekatan Cross Sectional. Populasi penelitian ini adalah Semua ibu yang mempunyai balita di wilayah posyandu desa Dahanrejo Kecamatan Kebomas Gresik sebanyak 81 orang yang diambil dengan Teknik Simple Random Sampling yaitu pengambilan dengan cara acak tanpa memperhatikan strata yang ada dalam anggota populasi.

Variabel independen dari penelitian ini adalah Paritas ibu. Variabel dependen dari penelitian ini adalah Keteraturan kunjungan balita ke posyandu. Pengumpulan data dilakukan secara langsung melalui pengisian kuesioner. Kuesioner yang digunakan berupa kuesioner tentang paritas ibu dan keteraturan kunjungan posyandu dan observasi keteraturan kunjungan dengan menggunakan buku KIA. 
Analisa data dalam penelitian ini dilakukan setelah data terkumpul kemudian dilakukan pengolahan data. Dimana untuk mencari hubungan variabel independen dan dependen mengetahui hubungan variabel tersebut dilakukan analisa uji uji Fisher Exact dan coefisien contingency.

\section{HASIL PENELITIAN}

Dari hasil penelitian diperoleh data sebagai berikut :

Tabel 5.1 Distribusi Frekuensi Karakteristik Responden Berdasarkan Usia Ibu yang memiliki anak Balita di Kelurahan Dahan Rejo Wilayah Kerja Puskesmas Kebomas - Gresik tahun 2019

\begin{tabular}{llcc}
\hline No & Usia Ibu & Frekuensi & Persentase \\
\hline 1 & $\leq 20$ tahun & 2 & 2,5 \\
2 & $20-30$ tahun & 35 & 43,2 \\
3 & $\geq 30$ tahun & 44 & 54,3 \\
\hline & Total & 81 & 100 \\
\hline
\end{tabular}

Sumber : Data Primer 2019

Tabel 5.2 Distribusi Frekuensi Karakteristik Responden Berdasarkan Pendidikan Ibu yang memiliki anak Balita di Kelurahan Dahan Rejo Wilayah Kerja Puskesmas Kebomas - Gresik tahun 2019

\begin{tabular}{llcc}
\hline $\begin{array}{l}\text { N } \\
\text { o }\end{array}$ & Pendidikan Ibu & $\begin{array}{c}\text { Frekue } \\
\text { nsi }\end{array}$ & $\begin{array}{c}\text { Perse } \\
\text { ntase }\end{array}$ \\
\hline 1 & Rendah (SD/SMP) & 32 & 39,5 \\
2 & Menengah (SMA & 31 & 38,3 \\
& Sederajat) & & \\
3 & Tinggi (PT) & 18 & 22,2 \\
\hline & Total & 81 & 100 \\
\hline
\end{tabular}

Sumber : Data Primer 2019

Tabel 5.2 Menunjukan bahwa hampir setengahnya responden memiliki pendidikan yang rendah dan sebagian besar menengah keatas.

Tabel 5.3 Distribusi Frekuensi Karakteristik Responden Berdasarkan Pekerjaan Ibu yang memiliki anak Balita di Kelurahan Dahan Rejo Wilayah Kerja Puskesmas Kebomas - Gresik tahun 2019

\begin{tabular}{llcc}
\hline No & $\begin{array}{l}\text { Pekerjaa } \\
\text { n Ibu }\end{array}$ & $\begin{array}{c}\text { Frekuen } \\
\text { si }\end{array}$ & $\begin{array}{c}\text { Persenta } \\
\text { se }\end{array}$ \\
\hline 1 & Bekerja & 23 & 28,4 \\
\hline
\end{tabular}

\begin{tabular}{cccc}
\hline 2 & $\begin{array}{c}\text { Tidak } \\
\text { bekerja }\end{array}$ & 58 & 71,6 \\
\hline Total & 81 & 100 \\
\hline
\end{tabular}

Sumber : Data Primer 2019

Tabel 5.3 menunjukkan bahwa sebagian besar ibu tidak bekerja dan hampir seperempatnya bekerja.

Tabel 5.4 Distribusi Frekuensi Karakteristik Responden Berdasarkan Pendapatan keluarga yang memiliki anak Balita di Kelurahan Dahan Rejo Wilayah Kerja Puskesmas Kebomas Gresik tahun 2019

\begin{tabular}{cccc}
\hline No & $\begin{array}{l}\text { Pendapata } \\
\text { n Ibu }\end{array}$ & $\begin{array}{c}\text { Frekue } \\
\text { nsi }\end{array}$ & $\begin{array}{c}\text { Persenta } \\
\text { se }\end{array}$ \\
\hline 1 & $<$ UMR & 57 & 70,4 \\
2 & $\geq$ UMR & 24 & 29,6 \\
\hline & Total & 81 & 100 \\
\hline
\end{tabular}

Sumber : Data Primer 2019

Tabel 5.4 menunjukkan bahwa sebagian besar ibu memiliki pendapatan kurang dari UMR.

Tabel 5.5 Distribusi Frekuensi Karakteristik Responden Berdasarkan Usia anak di Kelurahan Dahan Rejo Wilayah Kerja Puskesmas Kebomas - Gresik tahun 2019

\begin{tabular}{llcc}
\hline No & $\begin{array}{l}\text { Usia } \\
\text { Anak }\end{array}$ & Frekuensi & Persentase \\
\hline 1 & 0 & 3 & 3,7 \\
2 & $<1$ tahun & 27 & 33.3 \\
3 & $1-3$ tahun & 51 & 63,0 \\
\hline & Total & 81 & 100 \\
\hline
\end{tabular}

Sumber : Data Primer 2019

Tabel 5.5 menunjukkan bahwa lebih dari 50\% usia anak yang dimiliki oleh ibu berkisar antar 1-3 tahun.

Tabel 5.6Distribusi Frekuensi Karakteristik Responden Berdasarkan urutan anak terakhir di Kelurahan Dahan Rejo Wilayah Kerja Puskesmas Kebomas - Gresik tahun 2019

\begin{tabular}{llcc}
\hline No & $\begin{array}{l}\text { Urutan } \\
\text { Anak } \\
\end{array}$ & Frekuensi & Persentase \\
& Terakhir & & \\
\hline 1 & $1-2$ & 67 & 82,7 \\
2 & $>2$ & 14 & 17,3 \\
\hline & Total & 81 & 100 \\
\hline
\end{tabular}

Sumber : Data Primer 2019 
Tabel 5.6 Menunjukkan bahwa sebagian besar anak terakhir yang dimiliki adalah urutan 1-2, dan hanya sebagian kecil urutan lebih dari 2.

Tabel 5.7 Distribusi Frekuensi Karakteristik Responden Berdasarkan Paritas Ibu yang memilki Balita di Kelurahan Dahan Rejo Wilayah Kerja Puskesmas Kebomas - Gresik tahun 2019

\begin{tabular}{|c|c|c|c|}
\hline No & Paritas Ibu & $\begin{array}{c}\text { Frekue } \\
\text { nsi }\end{array}$ & $\begin{array}{c}\text { Persen } \\
\text { tase }\end{array}$ \\
\hline 1 & Primipara & 70 & 86,4 \\
\hline 2 & $\begin{array}{l}\text { Multipara/gran } \\
\text { demultipara }\end{array}$ & 11 & 13,6 \\
\hline & Total & 81 & 100 \\
\hline
\end{tabular}

Sumber : Data Primer 2019

Tabel 5.7bahwa sebagian besar ibu adalah Primipara sedangkan sebagian kecil multipara/grandemultipara.

Tabel 5.8 Distribusi Frekuensi Keteraturan Kunjungan Posyandu berdasarkan ibu yang memiliki balita di Kelurahan Dahan Rejo Wilayah Kerja Puskesmas Kebomas Gresik tahun 2019

\begin{tabular}{llcc}
\hline No & $\begin{array}{l}\text { Keteraturan } \\
\text { Kunjungan } \\
\text { Posyandu }\end{array}$ & $\begin{array}{c}\text { Freku } \\
\text { ensi }\end{array}$ & $\begin{array}{c}\text { Persentas } \\
\text { e }\end{array}$ \\
\hline 1 & Tidak teratur & 5 & 6,2 \\
2 & Teratur & 76 & 93,8 \\
\hline & Total & 81 & 100 \\
\hline
\end{tabular}

Sumber : Data Primer 2019

Tabel 5.8 menunjukkan bahwa mayoritas ibu memiliki kunjungan posyandu yang teratur. 
Tabel 5.9Tabulasi Silang Hubungan Paritas Ibu dangan Keteraturan Kunjungan Balita di Posyandu di Kelurahan Dahan Rejo Wilayah Kerja Puskesmas Kebomas - Gresik tahun 2019

\begin{tabular}{|c|c|c|c|c|c|c|}
\hline \multirow{3}{*}{ Paritas } & \multicolumn{4}{|c|}{ Keteraturan Kunjungan Posyandu } & \multicolumn{2}{|c|}{ Total } \\
\hline & \multicolumn{2}{|c|}{ Tidak teratur } & \multicolumn{2}{|c|}{ Teratur } & \multirow[b]{2}{*}{ Frekuensi } & \multirow[b]{2}{*}{ Persentase } \\
\hline & Frekuensi & Persentase & Frekuensi & Persentase & & \\
\hline Primipara & 0 & 0 & 70 & 86,4 & 70 & 86,4 \\
\hline $\begin{array}{c}\text { Multipara/ } \\
\text { Grandemultipara }\end{array}$ & 5 & 6,2 & 6 & 7,4 & 11 & 13,6 \\
\hline Total & 5 & 6,2 & 76 & 93,8 & 81 & 100 \\
\hline $\begin{array}{r}\text { Nilai } \mathbf{X}^{2}{ }_{h i} \\
\text { Nilai }\end{array}$ & $\begin{array}{l}\text { ung }=26,517 \\
P(\text { exact Fis }\end{array}$ & $\begin{array}{l}\text { p value }=0,0 \\
\text { er) }=0,000\end{array}$ & & Nilai & Coefisien $\mathrm{C}=$ & 0,543 \\
\hline
\end{tabular}

Sumber : Data Primer 2019

Tabel 5.9 Hasil tabulasi silang menjelaskan bahwa sebagian besar ibu dengan Primipara, teratur dalam melakukan kunjungan posyandu sedangkan ibu dengan Multipara/Grandemultipara masih banyak yang tidak teratur dalam melakukan kunjungan ke posyandu. Hasil uji chi square tidak memenuhi syarat karena ada frekuensi harapan kurang dari 5. Uji Fisher Exact dilakukan bila uji Chi Square tidak memenuhi syarat. Hasil uji Fisher Exact menunjukkan nilai P sebesar 0,000 (lebih kecil dari $\alpha$ sebesar 0,05). Sehingga disimpulkan bahwa ada hubungan antara paritas dengan keteraturan kunjungan ke posyandu.

Nilai koefisien Contingency C menunjukkan nilai 0,543 hal ini menjelaskan bahwa ada korelasi yang cukup kuat antara paritas ibu dengan keteraturan kunjungan ke posyandu. Ibu dengan paritas Primipara memiliki rasa kepedulian yang besar dalam perawatan anak, sehingga untuk memantau tumbuh kembang anaknya akan rutin berkunjung ke posyandu.

\section{PEMBAHASAN}

\section{Paritas Ibu}

Hasil penelitian menunjukkan bahwa sebagian besar ibu adalah Primipara yaitu sebesar $86,4 \%$ sedangkan sebagian kecil ibu termasuk multipara/grandemultipara yaitu sebesar 13,6\%. Hal ini kemungkinan dapat dipengaruhi oleh pendidikan ibu. Semakin tinggi tingkat pendidikan, maka ibu akan semakin dewasa dan lebih terbuka terhadap informasi yang baru khususnya terhadap kesehatan reproduksinya dalam hal ini jumlah anak yang dimiliki. Selain itu pendapatan keluarga juga dapat berpengaruh terhadap jumlah paritas ibu. Ibu dengan pendapatan keluarga kurang dari UMR memiliki keterjangkauan terhadap pemenuhan kebutuhan ekonomi maupun kebutuhan hidup keluarga yang juga rendah. Dengan jumlah anak yang sedikit maka pemenuhan kebutuhan sehari hari akan sedikit pula. Hasil penelitian ini menunjukkan bahwa sebagian besar pendapatan keluarga adalah dibawah UMR $(70,4 \%)$.

Menurut Marimbi (2010), Ibu yang berpendidikan tinggi lebih mudah menerima informasi dari luar (baik infomasi secara langsung maupun informasi dari media cetak dan elektronik), lebih mudah menerima masukan dan merubah perilaku menjadi lebih baik, sehingga cenderung memberikan lingkungan yang kondusif untuk tumbuh kembang anak. Pendidikan ibu yang tinggi memungkinkan ibu untuk menerima segala informasi dari luar terutama tentang cara pengasuhan anak yang baik, bagaimana menjaga kesehatan anak, pendidikan, dan sebagainya. Selain itu ibu yang mempunyai pendidikan tinggi akan lebih berpikir rasional tentang jumlah anak yang ideal.

Hal ini sejalan dengan penelitian yang dilakukan oleh Yetty Dwi Fara, Dkk, (2019) didapatkan bahwa dari seluruh responden mayoritas $(85,0 \%)$ ibu dengan primipara berpartisipasi aktif melakukan penimbangan. Sementara itu, ibu dengan multipara hanya sebagian kecil (15,0\%) yang melakukan penimbangan.

Dari hasil penelitian ditemukan bahwa ibu primipara selalu teratur berkunjung ke posyandu di bandingkan dengan ibu multipara/grandemultipara yang tidak teratur berkunjung ke posyandu karena semakin tinggi jumlah anak yang dilahirkan maka akan semakin tidak teratur membawa balitanya ke 
posyandu. Dengan pengetahuan ibu yang tinggi yang banyak mendapat informasi, dengan menonton acara televisi dan media elektronik lainnya, memungkinkan ibu memiliki pengetahuan cukup tentang manfaat dari posyandu. Sebagai tenaga kesehatan hendaknnya meningaktkan pemberian penyuluhan serta informasi pada ibu yang mempunyai balita untuk selalu memantau pertumbuhan dan perkembangan balitannya agar selalu menimbang balitannya secara rutin 1 bulan sekali saat posyandu dilakukan. (Dinkes, RI, 2006).

\section{Keteraturan Kunjungan Balita Di Posyandu Kelurahan Dahanrejo Gresik.}

Berdasarkan tabel 5.8 dapat diketahui bahwa mayoritas ibu memiliki kunjungan posyandu yang teratur (93,8\%). Menurut Arikunto (2006) Keteraturan adalah dasar semua tindakan dan usaha untuk meningkatkan usaha-usaha manusia. Karena dari pengalaman dan penelitian ternyata keteraturan yang didasari ketentuan akan lebih langgeng dari pada keteraturan yang tidak didasari dengan ketentuan.

Utami \& Damayanti (2016) menyatakan bahwa banyak hal yang dapat mempengaruhi tingkat pencapaian partisipasi masyarakat dalam penimbangan, antara lain tingkat pendidikan, tingkat pengetahuan, usia balita, pekerjaan, jumlah anak / paritas, jarak tempuh, sosial ekonomi, ketersedian fasilitas, sikap, dan perilaku para petugas kesehatan. Usia bayi antara 0-59 bulan merupakan periode yang sangat penting bagi pertumbuhan anak, sehingga anak perlu ditimbang secara teratur dan dapat diikuti pertumbuhan berat badannya. Anak yang sehat akan tumbuh pesat, bertambah umur bertambah berat badannya.

Penelitian ini sejalan dengan penelitian yang dilakukan oleh Lia Kamila, Dkk, (2017) bahwa di dapatkan sebagian besar ibu balita teratur (69\%) dalam mengunjungi posyandu, dan hampir setengah dari ibu balita tidak teratur $(31 \%)$ dalam mengunjungi posyandu. Sejalan dengan penelitian Astuti (2010) di dapatkan hasil bahwa keteraturan ibu dalam mengunjungi posyandu balita sebesar 67,3\%, sedangkan ibu balita yang tidak teratur sebesar $32,7 \%$.

Data Dinas Kesehatan Kabupaten Lampung Timur, (2018) menyatakan bahwa partisipasi masyarakat dalam penimbangan digambarkan dalam perbandingan jumlah balita yang ditimbang (D) dengan jumlah balita seluruhnya (S). Semakin tinggi partisipasi masyarakat dalam penimbangan, maka semakin banyak pula data yang dapat menggambarkan status gizi balita. Pemantauan berat badan balita dapat berhasil dengan baik apabila ada partisipasi aktif dari masyarakat yang ditandai dengan tingkat kehadiran ibu menimbangkan anaknya di posyandu (Kementerian Kesehatan Republik Indonesia, 2012).

Menrut hasil penelitian Masnuchadin, dan teori yang dijelaskan oleh Dusseldorp yang menyatakan bahwa ada beberapa tingkatan partisipasi seseoarang yaitu partisipasi terinduksi, yaitu peran serta yang tumbuh karena terinduksi oleh adanya motivasi ekstrinsik (berupa bujukan, pengaruh, dorongan) dari luar meskipun yang bersangkutan tetap memilki kebebasan penuh untuk berpartisipasi. Program posyandu akan bermanfaat jika balita berkunjung ke posyandu secara teratur. Keteraturan balita berkunjung ke posyandu sangat tergantung dari partisipasi ibu untuk membawa balitanya berkunjung ke Posyandu.

Hasil penelitian menunjukkan bahwa hampir keseluruhan ibu balita $(93,8 \%)$ melakukan penimbangan di posyandu. Hasil ini melebihi dari hasil Riskesdas 2010 dimana frekuensi penimbangan balita $>4 \mathrm{x}$ di Indonesia berada diantara nilai $22 \%-86,8 \%$.

Faktor lingkungan juga dapat memotivasi seseorang untuk berprilaku sehat, sehingga apabila motivasi ibu serta keinginan ibu untuk datang ke Posyandu guna memantau pertumbuhan dan perkembangan balitanya serta ingin mengetahui kesehatan balita dan faktor lingkungan mendukung maka akan tercipta keinginan ibu untuk memanfaatkan dan melakukan kunjungan balita ke Posyandu secara rutin setiap bulan. Dukungan orang-orang terdekat, sarana prasarana yang disedia-kan dalam pelayanan kesehatan dan lain sebagainya juga dapat mempengaruhi ibu untuk berpartisipasi datang ke posyandu.

Upaya promotif untuk meningkatkan partisipasi aktif ibu balita untuk menimbang balita secara rutin di posyandu adalah dengan memfokuskan pada kelompok ibu balita yang tingkat pengetahuan dan pendidikan rendah melalui pendidikan kesehatan atau promosi kesehatan berupa penyuluhan dan melakukan konseling betapa pentingnya melakukan penimbangan balita dalam rangka memantau tumbuh kembang balitanya. Faktor lain yang juga perlu diperhatikan dalam rangka meningkatkan partisipasi aktif ibu balita untuk menimbang balita di Posyandu adalah motivasi ibu, dukungan keluarga dan umur balita. Upaya yang dilakukan untuk meningkatkan faktor tersebut diatas adalah dengan memberikan motivasi pada ibu balita melalui kegiatan di Posyandu. Dukungan keluarga juga perlu ditingkatkan dengan memberikan penyuluhan pada keluarga khususnya pada suami tentang pentingnya penimbangan balita di Posyandu. Ibu balita juga perludijelaskan pentingnya menimbang anak balita $(>1-<5$ tahun) bukan 
hanya pada masa bayi ( $<1$ tahun)karena masa balita ( $<5$ tahun) merupakan masa emas untuk pertumbuhan dan perkembangan anak. Kebijakan revitalisasi Posyandu tidak akan berjalan dengan optimal bila hanya memperhatikanpenyediaan sarana pelayanan kesehatan saja.

Dari hasil observasi buku KMS (Kartu Menuju Sehat) yang penulis lakukan, didapatkan hasil bahwa mayoritas responden teratur melakukan kunjungan ke Posyandu kepada balitanya, hal itu dikarenakan ibu memahami bahwa dengan melakukan kunjungan ke Posyandu memiliki banyak manfaat untuk kesehatan ibu dan anak, selain itu juga agar pertumbuhan dan perkembangan balitanya dapat terpantau dengan baik. Ibu balita yang teratur dalam mengunjungi posyandu akan sangat bermanfaat dalam memonitoring tumbuh kembang dan status gizi balita serta deteksi dini terhadap kelainan tumbuh kembang dan status kesehatan balita sehingga dapat segera ditentukan tindakan lebih lanjut.

\section{Hubungan Paritas Ibu Dengan Keteraturan Kunjungan Balita Di Posyandu II Desa Karangturi Gresik.}

Berdasarkan tabel 5.6 dapat disimpulkan bahwa sebagian besar ibu dengan Primipara teratur dalam melakukan kunjungan posyandu sedangkan ibu dengan Multipara/Grandemultipara masih banyak yang tidak teratur dalam melakukan kunjungan ke posyandu. Hasil uji dapat disimpulkan bahwa ada hubungan antara paritas dengan keteraturan kunjungan ke posyandu dengan Nilai koefisien Contingency $\mathrm{C}$ menunjukkan nilai 0,543 hal ini menjelaskan bahwa ada korelasi yang cukup kuat antara paritas ibu dengan keteraturan kunjungan ke posyandu..

Hasil penelitian ini dapat menjawab hipotesis yang mengatakan bahwa terdapat hubungan antara paritas ibu dengan keteraturan kunjungan balita ke posyandu. Ibu dengan paritas sedikit (primipara) mempunyai peluang lebih besar untuk aktif berkunjung ke Posyandu dibandingkan ibu multipara/grandemultiipara. Menurut asumsi peneliti, ibu primipara lebih cenderung rajin ke Posyandu dikarenakan ibu masih fokus dalam perawatan anaknya dan tidak terganggu dengan anak lainnya, selain itu ibu memahami manfaat pentingnya datang ke Posyandu. Hal ini membuat ibu yang memiliki balita satu dapat terus memantau asupan maupun aktivitas anaknya dengan baik.

Hasil penelitian ini tidak Sejalan dengan penelitian yang dilakukan oleh Yetty Dwi Fara, Dkk, (2019) yang disimpulkan bahwa tidak ada hubungan yang signifikan antara paritas dengan partisipasi ibu. Hasil penelitian Utami \& Damayanti, (2016) juga menunjukkan bahwa secara statistik tidak terdapat hubungan yang bermakna antara paritas dengan perilaku ibu dalam melakukan kunjungan ke Posyandu. Dari hasil penelitian yang didapatkan, Peneliti berasumsi bahwa terdapat beberapa faktor yang mempengaruhi hubungan paritas ibu dengan keteraturan kunjungan balita di posyandu, yaitu seperti faktor pendidikan ibu yang dimana semakin tinggi tingkat pendidikan ibu maka akan semakin mudah memperoleh suatu informasi hal sangat berpengaruh penting terhadap pengetahuan ibu. Dengan Pendidikan ibu yang tinggi pemahaman tentang pentingnya kesehatan dalam hal ini pemantauan pertumbuhan dan perkembangan balita melalui partisipasi aktif dalam kegiatan posyandu akan semakin tinggi. Selain itu semakin tinggi tingkat pendidikan seseorang maka makin mudah dalam memperoleh dan menerima informasi sehingga kemampuan ibu dalam berpikir lebih normal tentang jumlah anak yang ideal.

Menurut Friedman (2005) Pengetahuan merupakan domain dari prilaku. Semakin tinggi tingkat pengetahuan / pendidikan seseorang, maka perilaku akan lebih bersifat langgeng. Dengan kata lain ibu yang tahu dan paham tentang jumlah anak yang ideal, maka ibu akan berprilaku sesuai dengan apa yang ia ketahui bahwa ibu yang memiliki anak yang ideal itu cenderung lebih mudah untuk mengurus dan membesarkan anak dengan baik.

Adapun faktor yang lainya yang juga sangat berpengaruh yaitu pekerjaan ibu, dari hasil penelitian didapatkan bahwamayoritas ibu tidak bekerja $(71,6 \%)$. Ibu yang tidak bekerja akan memiliki waktu jauh lebih banyak dalam mengurus anak 
terutama dalam hal memantau pertumbuhan dan perkembangan anak, selain itu juga dengan ibu tidak bekerja peluang memiliki waktu untuk hadir berpartisipasi dalam kegiatan posyandu akan semakin banyak pula.

Kenyataan dilapangan yang menunjukkan banyaknya balita yang teratur berkunjung di posyandu adalah ibu dengan primipara yaitu ibu yang masih memiliki anak 1 dan mereka cenderung teratur berkunjung di posyandu kemungkinan dikarenakan ibu masih bias fokus terhadap kesehatan anaknya sehingga kemungkinan ibu teratur membawa balitanya ke posyandu.

Sebagai tenaga kesehatan harus tetapdapat meningkatkan memberikan penyuluhan serta informasi kepada masyarakat khususnnya ibu yang mempunyai anak balita agar selalu rutin datang ke posyandu untuk menimbang balitannya setiap 1 bulan sekali dan serta memberikan pembinaan kepada para kaderkader agar kooperatif terhadap masyarakat untuk keberhasilan posyandu. (Dinkes, RI, 2006) 


\section{KESIMPULAN}

1. Sebagian besar responden di Kelurahan Dahanrejo di Wilayah Kerja Puskesmas Kebomas Gresik adalah paritas ibu dengan primigravida

2. Sebagian besar responden di di Kelurahan Dahanrejo di Wilayah Kerja Puskesmas Kebomas Gresik teratur dalam kunjungan posyandu balita.

3. Terdapat hubungan yang signifikan antara paritas ibu dengan keteraturan kunjungan posyandu di Kelurahan Dahanrejo di Wilayah Kerja Puskesmas Kebomas Gresik.

\section{DAFTAR PUSTAKA}

Adisasmito, W. (2007) Sistem Kesehatan, edisi 1. Jakarta, PT. Raja Grafindo Persada

Afifuddin dan Saebani, B.A. (2009) Metodologi Penelitian Kualitatif, Pustaka Setia, Bandung.

Arikunto. 2006. Prosedur Penelitian Suatu Pendekatan Praktek. Jakarta : PT. Rineka Cipta.

Kemenkes RI, (2016). Profil Kesehatan JAwa Timur tahun 2016 : Dinas Kesehatan Provinsi Jawa Timur. Surabaya

http://www.depkes.go.id/resources/dow nload/profil/PROFIL KES PROVINSI 2016/15 Jatim 2016.

Kementerian Kesehatan Badan Penelitian dan Pengembangah Kesehatan. (2018). Hasil utama riskesdas 2018. Jakarta. Retrieved from http://www.depkes.go.id/resources/dow nload/infoterkini/materi_rakorpop_2018 /HasilRiskesdas 2018.pdf

Kementerian Kesehatan Republik Indonesia. (2012). Ayo ke Posyandu Setiap Bulan. Jakarta.

Lia Kamila, Liawati, Suci Lailani Alipah. (2017), Faktor Pengetahuan Yang Mempengaruhi
Keteraturan Ibu Balita Dalam Mengunjungi Posyandu Di Desa Cipangeran Kecamatan Saguling Kabupaten Bandung Barat Tahun 2017. Prodi DIII Kebidanan STIKES RajawaliBandung, Jln. Rajawali Barat No.73 Bandung, 40184, Jawa Barat, Indonesia. Jurnal Kesehatan Indra Husada, Vol.5, No.2 Jul-Des 2017

Notoatmodjo,S.2012. Metodologi

Penelitian Kesehatan. Jakarta:

Rineka Cipta.

Nursalam, (2008), Konsep Dan Penerapan Metodologi Penelitian Ilmu Keperawatan: Pedoman Skripsi, Tesis Dan Instrumen Penelitian Keperawatan. Jakarta: Salemba Medika, hlm 95-125.

Oktiawati, A., Julianti, E., \& Natalia, R. (2016). Pedoman Pelaksanaan Posyandu. Yogyakarta: Nuha Medika.

Prawirohardjo. 2009. Ilmu Kebidanan. Jakarta : Bina Pustaka Sarwono Prawirohardjo.

Reihana, Artha Budi Susila Duarsa (2016), Faktor-Faktor Yang Berhubungan Dengan Tingkat Partisipasiibu Balita Untuk Menimbang Balita Ke Posyandu Di Wilayah Kerjapuskesmas Panjang Bandar Lampung Tahun 2010, Jurnal Kebijakan Kesehatan Indonesia Volume 05 No. 02 Juni Halaman 67 - 72, Dinas Kesehatan Kota Bandar Lampung2Program Studi S2 Kesehatan Masyarakat STIKES Mitra Lampung.

Rinawati Kasrin. (2012), Hubungan Pengetahuan Dan Sikap Ibu Yang Mempunyai Balita Dengan Kunjungan Ke Posyandu AlMushawir Di Wilayah Kerja Puskesmas Sungai Limau Kabupaten Padang Pariaman. Jurnal Kesehatan STIKes Prima 
Nusantara Bukittinggi, Vol.3 No 2

Juli 2012

Sarwono. 2009. Ilmu Kebidanan.

Edisi Keempat. Jakarta : Bina

Pustaka Sarwono Prawirohardjo

Soetjiningsih. 2002.Tumbuh

Kembang Anak. Jakarta: EGC.

Syahlan, J.H. 1996. Kebidanan

Komunitas. Jakarta: Yayasan Bina

Sumber Daya Kesehatan.

Syaifudin, B.A. 2002. Buku panduan Praktis Pelayanan Kesehatan Maternal dan Neonatal. Jakarta: YBP.

Utami, R. B., \& Damayanti, D. F. (2016). Faktor-faktor yang Berhubungan dengan Perilaku Ibu dalam Melakukan Kunjungan Ke Posyandu. Jurnal Vokasi Kesehatan, 2(1), 41-48. Yuni, N. E., \& Rika, S. U. (2014). Panduan Lengkap Posyandu untuk bidan dan kader. Yogyakarta: Nuha Medika.

Varney, H., Jan, M. Kriebs, Carolyn, LG. 2002. Buku Ajar
Asuhan Kebidanan, Edisi 4. Volume 2. Jakarta: EGC.

Varney, H., Jan, M. Kriebs, Carolyn, LG. 2007. Buku Ajar Konsep Kebidanan. Edisi 4. Editor Esty Wahyuningsih, et al. Jakarta: EGC.

Walyani, Elisabeth Siwi. 2015. Asuhan Kebidanan pada kehamilan. Yogyakarta : PustakaBarupess

Yetty Dwi Fara1, dkk (2019), Faktor-Faktor yang Berhubungan dengan Partisipasi Ibu Menimbang Balita, Wellness And Healthy Magazine Volume 1, Nomor 2, Agustus 2019, ISSN 2655-9951 (print), ISSN 2656-0062,2,3Universitas Aisyah Pringsewu Lampung.

Yuni, N. E., \& Rika, S. U. (2014). Panduan Lengkap Posyandu untuk bidan dan kader. Yogyakarta: Nuha Medika. 